\title{
ERA DISTRIBUTION OF INFORMATION SYSTEMS JOURNALS
}

\author{
John W Lamp \\ School of Information Systems \\ Deakin University, Geelong, Victoria \\ Email: John.Lamp@,deakin.edu.au \\ Julie Fisher \\ Caulfield School of Information Technology \\ Monash University, Victoria, Australia \\ Email: julie.fisher@infotech.monash.edu.au
}

\begin{abstract}
The Excellence in Research for Australia (ERA) initiative being conducted by the Australian Research Council (ARC), mandates a single journal and conference ranking scheme over every academic discipline in Australia. A universal publication outlet ranking list mandated by a government agency is unique and has attracted interest and comment both within Australia and overseas. Equally, the interest shown has come from all sectors involved in academic publishing - authors, reviewers, publishers - and from commercial and open access publishers. This paper investigates the distribution of information systems journals over the various ERA parameters and comments on a claim of bias whereby the ranking of a journal is positively influenced by the number of years it has been in existence in the areas of information systems and business journals. Clear evidence of the diversity of the information systems discipline is observed. The benefits of a multidisciplinary foundation for information systems is also noted. Longer established journals are shown to attract higher rankings and possible reasons for and implications flowing from this are discussed.
\end{abstract}

\section{INTRODUCTION}

The Excellence in Research for Australia (ERA) initiative (ARC, 2008a) was introduced by the Australian Government, lead by Prime Minister Kevin Rudd, after the 2007 Federal election defeat of the Liberal Party led by John Howard. The ERA initiative was an amended version of the Research Quality Framework (RQF) project (DEST, 2006) undertaken by the Howard government.

To assess the excellence of the research being undertaken in Australia, the ERA prepared a matrix of indicators (ARC, 2009). The applicability of the various indicators varied according to the specific discipline. The Australian and New Zealand Fields of Research (ANZFoR) codes from the Australian and New Zealand Standard Research Classification (ABS, 2008) were used to identify the disciplines. These codes are arranged into a strict hierarchy of three levels. The top level consists of twenty-two divisions (identified by a two-digit code) covering all research activities. Within each division, there are a varying number of groups as required by the specific division which are identified by a four-digit code consisting of the two-digit division code with two digits appended. Each group is further divided, as required, into fields which are identified by a six-digit code consisting of the four-digit group code with two digits appended. The ERA exercise used only divisions and groups, i.e. two and four-digit codes. 
In this classification, information systems is allocated the group code 0806 within the parent division 08 which is described as "Information and Computing Sciences." It should be noted that while the majority of information systems activities fall into 0806, some aspects of information systems fall into other four-digit groups, e.g. health informatics in 0807. The indicators for information systems, ANZFoR 0806, are at Table 1.

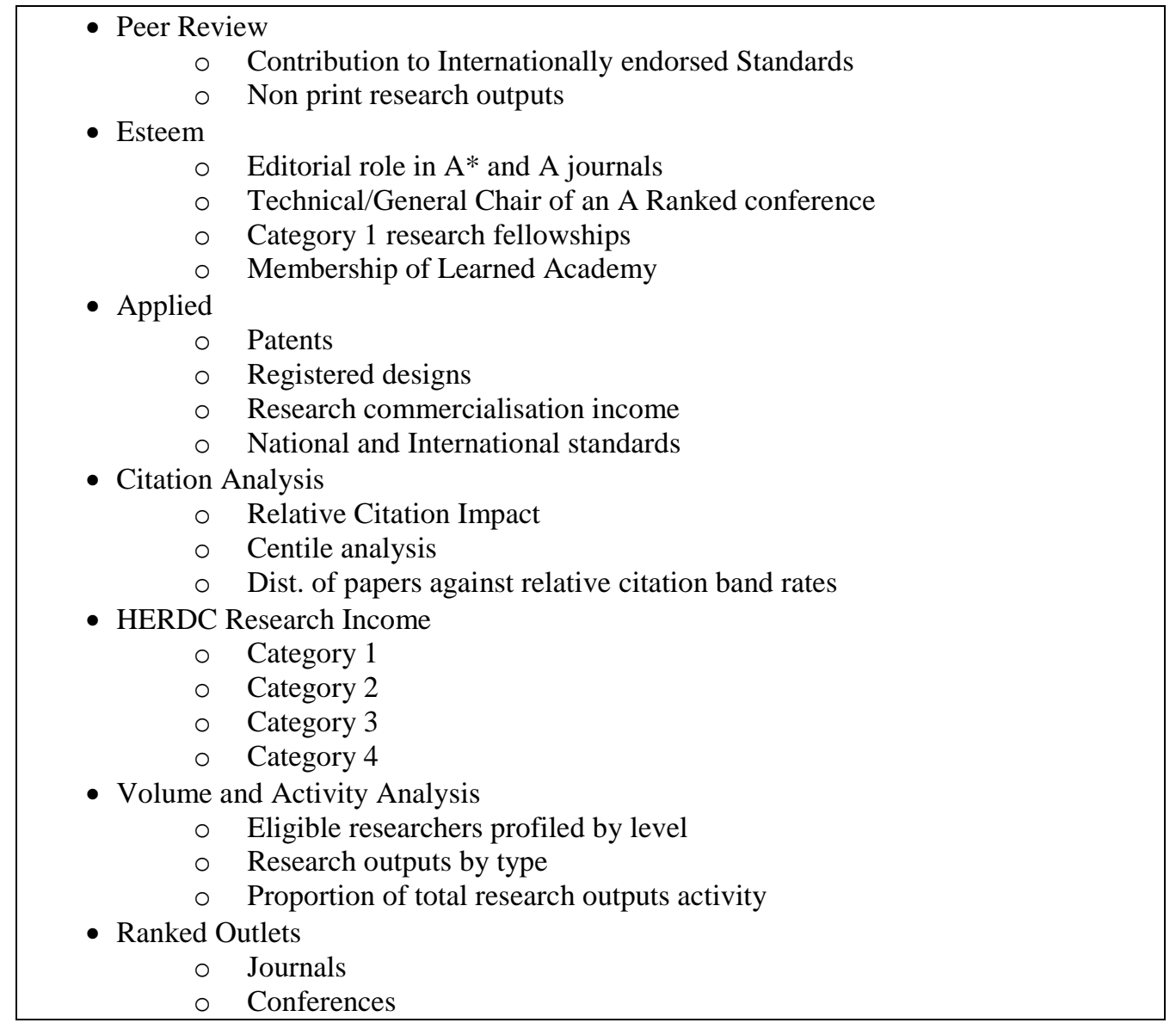

Table 1: Excellence indicators for 0806: Information Systems (from ARC, 2009)

Publication ranking has a history of use and remains one of the most significant criteria for judging research output. Researchers are involved in academic publishing in many capacities. They are involved as authors, reviewers, publishers, distributors, and, not least, as readers and users of the published material. Researchers did not hesitate to share their experiences and judgements of the ERA rankings even before they were finalised (e.g. Graham, 2008; King \& Kreisler, 2008; Anderson \& Tressler, 2009; Clarke, 2009; Genoni \& Haddow, 2009; Hicks, 2009; Jarwal, Brion, et al. 2009; Lamp, 2009).

The ERA journal ranking exercise began with input from Australian learned academies and other peak discipline bodies being used to create an initial journal listing as input to consultation leading to a final list. The initial list was released in June 2008 and contained over 19,500 journals allocated 
among 181 categories. In comparison with the ERA list, Thomson ISI and Scopus each index approximately 15,000 indexed journals (ARC, 2008b).

The categories used by the ERA initially used the division (two-digit) and group (four-digit) ANZFoR codes. The ERA also created two meta-categories: "Multidisciplinary - Science" and "Multidisciplinary - Social Sciences/Humanities". The aim was to allocate each journal to the fourdigit group codes. Where a journal was allocated to more than three four-digit codes group codes in a particular division, it was allocated to the more general two-digit division code, rather than the fourdigit group codes. This approach allowed the initial list of journals by fields of research to be limited to just over 21,500 entries. While a single journal could be allocated to more than one field of research, it has only a single excellence ranking of $\mathrm{A}^{*}, \mathrm{~A}, \mathrm{~B}$ or $\mathrm{C}$. That single ranking therefore applied equally to all fields of research in which that journal is ranked, regardless of the amount of use that journal may attract in a particular field of research.

The final list, released in January 2010, has 20,433 ranked journals and 279 unranked journals. The two meta-categories: "Multidisciplinary - Science" and "Multidisciplinary - Social Sciences/Humanities" were merged into a single "Multidisciplinary" meta-category. Despite the ERA modifications to the ANZFoR coding scheme, the term ANZFoR will still be used in this paper to describe the codes used by ERA in accordance with common usage. With 180 ANZFoR categories this resulted in 27,426 entries in the ERA scheme once journals allocated to multiple ANZFoR categories were taken into account The current version of the ERA journal rankings is available from the ARC as an Excel spreadsheet (ARC, 2010b) and a searchable database of the final and draft versions of the ERA journal rankings (Lamp, 2010) has also been made available.

\begin{tabular}{|l||l||l|l|}
\hline \multirow{2}{*}{$\begin{array}{l}\text { Journal } \\
\text { Rank }\end{array}$} & $\begin{array}{l}\text { Target } \\
\text { Percentage }\end{array}$ & $\begin{array}{l}\text { Actual } \\
\text { Raw number }\end{array}$ & Percentage \\
\hline A* & $5 \%$ & 1030 & $5 \%$ \\
\hline A & $15 \%$ & 3054 & $15 \%$ \\
\hline B & $30 \%$ & 5667 & $28 \%$ \\
\hline C & $50 \%$ & 10682 & $52 \%$ \\
\hline & $100 \%$ & 20433 & $100 \%$ \\
\hline
\end{tabular}

Table 2: Overall ERA 2010 ranking distribution

The ARC also initially specified targets for the distribution of journals across the rankings (ERA, 2008b, p11). Following the 2008 public consultation, the ARC dropped the prescribed distribution. This change was promulgated through presentations, instructions to expert reviewers and peak bodies (A. Calder, personal communication, 13 December 2010). Nevertheless, the final ranking distribution adhered closely to those targets (Table2).

Since the January 2010 final list has been made available a number of discipline specific analyses of the ERA rankings have been made (e.g. Calver, Wardell-Johnson, et al., 2010; De Lange, O'Connell, et al., 2010; Haslam \& Koval, 2010; Michael Hall, 2010; Northcott \& Linacre, 2010).

Calver, Wardell-Johnson, et al. (2010) addressed the issue of what makes a journal international, particularly addressing the field of conservation biology. In their paper they propose a quantitative measure (IIJ) for determining whether or not a journal is international. De Lange, O'Connell, et al. (2010) use Aldous Huxley's Brave New World (1946) as a metaphor to describe their evaluation of 
the perceptions of Heads of Accounting Schools on the impact of the ERA and the degree of change which has taken place as a result. They conclude that changes are taking place, even before the ERA is fully implemented and its implications understood. Haslam \& Koval (2010) analysed 661 psychology journals and identified that "hard science" psychology journals tended to have higher bibliometric and ERA ranking. Michael Hall's analysis (2010) has an international comparative focus. His concern is with the spread of ranking and assessment systems without serious evaluation of their appropriateness to local conditions. He also raises the issue that it is the excellence of the published papers which determine the journal's ranking, rather than the reverse. Getting a paper into a highly ranked journal does not improve the quality of the paper. Northcott \& Linacre (2010) also address international trends in research assessment. They particularly focus on the UK, Australia and New Zealand. Their data was collected by a survey of accounting academics, interviews with journal editors and publishing house representatives. Participants noted the potential adverse effect of the pressure to submit to higher ranked journals on researchers, particularly early career researchers, whose "publishing strategy may be to submit their work to elite journals, only to result in rejection letters, few actual publications and a de-motivating sense of underachievement."

There is a growing body of literature critically appraising the ERA aims and processes and of similar contemporary exercises in other countries. The focus of this paper is upon the implications of the rankings for the information systems discipline.

The Australasian Council of Professors and Heads of Information Systems published a ranking scheme for journals in the information systems discipline, initially for the RQF (Fisher, Shanks, et al., 2007) which was then updated for submission to the ERA (Fisher, Shanks, et al., 2009). The final ranking is available at ACPHIS (2009). The ACPHIS data was matched with the ERA data at Lamp (2010) and more general information systems journal data at Lamp (1998) to produce the following analyses.

\section{DISTRIBUTION OF IS JOURNALS ACROSS RANKINGS}

The overall distribution of the ACPHIS submission and of the journals under 0806 is presented in Table 3.

\begin{tabular}{|c|c|c|c|c|c|c|c|}
\hline Journal & Target & \multicolumn{2}{|c|}{ ACPHIS Submission } & \multicolumn{2}{|c|}{ ANZFoR 0806} & \multicolumn{2}{|c|}{ ACPHIS Final } \\
\hline Rank & Percentage & Raw No & Percentage & Raw No & Percentage & Raw No & Percentage \\
\hline$A^{*}$ & $5 \%$ & 8 & $4 \%$ & 18 & $9 \%$ & 26 & $14 \%$ \\
\hline A & $15 \%$ & 31 & $16 \%$ & 24 & $13 \%$ & 37 & $21 \%$ \\
\hline B & $30 \%$ & 48 & $25 \%$ & 53 & $28 \%$ & 52 & $29 \%$ \\
\hline $\mathrm{C}$ & $50 \%$ & 104 & $54 \%$ & 95 & $50 \%$ & 65 & $36 \%$ \\
\hline & $100 \%$ & 191 & $100 \%$ & 190 & $100 \%$ & 180 & $100 \%$ \\
\hline
\end{tabular}

Table 3. ERA 2010 ranking distribution for information systems journals

The ACPHIS submission nominated 190 journals and stuck closely to the distribution mandated by the ERA. The 0806 ANZFoR code (ABS, 2008, p53) contains the area "Computer-Human Interaction" which received ranking submissions from non-information systems researchers. Equally, other information systems areas were allocated to other ANZFoR codes - e.g. "Health Informatics" is allocated to 0807 (ABS, 2008, p54). For this reason Table 3 in addition to reporting the ACPHIS 
submission and 0806 statistics, also reports on the final ranking of the 180 journals accepted from the ACPHIS submission.

It is readily apparent from Table 3 that the final ranking distribution of the ACPHIS nominated journals is more generous than the ACPHIS submission. The reason for this can be explained by reference to Table 4 below. This table lists the journals ranked as A* by ERA, which had a lower rank suggested by ACPHIS. All but two journals are linked with ANZFoR codes other than 0806. The remaining journals, Information Systems and ACM Transactions on Computer - Human Interaction, are not core information systems journals. Despite its name Information Systems is devoted to more technical issues, rather than the socio-technical issues which more usually concern the information systems discipline. ACM Transactions on Computer - Human Interaction is a core journal for the computer human interaction discipline which, as mentioned above, falls under 0806. Similar effects from other disciplines are observed in journals ranked by ACPHIS as A, B or C.

The conclusion that can be drawn from this is that the journals which were not as highly ranked in the ACPHIS submission, had their ranking increased based on submissions from researchers and disciplines for whom there were core journals, and this improved the final ranking distribution of journals submitted by ACPHIS. The multidisciplinary nature of information systems has assisted it in improving the ranking of journal outlets used by information systems researchers.

\begin{tabular}{|c|c|c|}
\hline$A N Z F o R(s)$ & $\begin{array}{c}A C P H I S \\
\text { Rank }\end{array}$ & Journal Title \\
\hline 0806 & $A$ & Information Systems \\
\hline 0806 & $B$ & ACM Transactions on Computer - Human Interaction \\
\hline 0803,0806 & $B$ & ACM Transactions on Computer Systems \\
\hline 0804,0806 & $B$ & ACM Transactions on Database Systems \\
\hline 0801,0806 & $B$ & ACM Transactions on Graphics \\
\hline 0802,0806 & $B$ & ACM Transactions on Mathematical Software \\
\hline 0803,0806 & $B$ & ACM Transactions on Programming Languages and Systems \\
\hline 0803,0806 & $B$ & ACM Transactions on Software Engineering and Methodology \\
\hline 0805 & $B$ & IEEE ACM Transactions on Networking \\
\hline 0803 & $B$ & IEEE Transactions on Computers \\
\hline 08,0911 & $B$ & IEEE Transactions on Information Technology in Biomedicine \\
\hline 0801, 0806 & $B$ & IEEE Transactions on Pattern Analysis and Machine Intelligence \\
\hline 0803, 0806 & $B$ & IEEE Transactions on Software Engineering \\
\hline $0102,0802,1503$ & $B$ & Operations Research \\
\hline 0802 & $C$ & Journal of Computer and System Sciences \\
\hline 08 & $C$ & Journal of the ACM \\
\hline 0807 & $C$ & $\begin{array}{l}\text { Journal of the American Society for Information Science and } \\
\text { Technology }\end{array}$ \\
\hline 0802 & $C$ & SIAM Journal on Computing \\
\hline 08 & $C$ & The Computer Journal \\
\hline
\end{tabular}

Table 4. ERA A* journals ranked lower by ACPHIS with associated ANZFoR codes 
Table 5 lists the eleven journals submitted by ACPHIS to the ERA process which were not included in the final rankings. In six cases the exclusions related to either changes of name or the journal having ceased. Of the remaining five cases the standout is Communications of the ACM which was submitted by ACPHIS as an A ranked journal. The reasons for the elimination of this journal are not known by the authors.

\begin{tabular}{|l|l|l|}
\hline $\begin{array}{l}\text { ACPHIS } \\
\text { Rank }\end{array}$ & Journal Title & Reason for change \\
\hline C & $\begin{array}{l}\text { Australian Journal of Educational } \\
\text { Technology }\end{array}$ & $\begin{array}{l}\text { Renamed Australasian Journal of Educational } \\
\text { Technology, ranked B }\end{array}$ \\
\hline C & China Journal of Information Systems & Unknown \\
\hline A & Communications of the ACM & Unknown \\
\hline A & IBM Systems Journal & $\begin{array}{l}\text { The IBM Systems Journal has been replaced by } \\
\text { the IBM Journal of Research and Development. } \\
\text { Ranked A }\end{array}$ \\
\hline C & $\begin{array}{l}\text { International Journal of Man- } \\
\text { Machine Studies }\end{array}$ & $\begin{array}{l}\text { Renamed International Journal of Human- } \\
\text { Computer Studies. Ranked A }\end{array}$ \\
\hline C & IT and Society: An Online Journal & Ceased \\
\hline B & Journal of End User Computing & $\begin{array}{l}\text { Renamed Journal of Organizational and End } \\
\text { User Computing. Ranked B }\end{array}$ \\
\hline C & $\begin{array}{l}\text { Journal of Information Technology } \\
\text { Cases and Applications }\end{array}$ & $\begin{array}{l}\text { Renamed Journal of IT Case and Application } \\
\text { Research in 2005. Ranked C }\end{array}$ \\
\hline C & Journal of Management Systems & Unknown \\
\hline C & $\begin{array}{l}\text { Journal on Educational Resources in } \\
\text { Computing }\end{array}$ & $\begin{array}{l}\text { JERIC has been renamed to The ACM } \\
\text { Transactions on Computing Education } \text { (TOCE). } \\
\text { Not ranked. }\end{array}$ \\
\hline B & MISQ Discovery & Unknown \\
\hline
\end{tabular}

Table 5. ACPHIS ranked journals which do not appear in the ERA ranking

\section{DISTRIBUTION OF IS JOURNALS ACROSS ANZ FIELDS OF RESEARCH}

In the discussion above, the limitations of the ANZFoR codes as a means of accurately capture the nature of the information systems discipline was mentioned. From the analysis in Table 3, we know that 180 ACPHIS nominated journals were accepted into the ERA scheme. These 180 journals were allocated by ERA to 312 ANZFoR codes as shown in

Table 6. From this analysis $62.5 \%$ of entries are outside of the ANZFoR information systems code, 0806. This would support the frequent observation that the information systems discipline is multidisciplinary. To test whether the lower ranked journals were the major contributors, the analysis was repeated with "C" ranked journals eliminated and again $62 \%$ of entries were outside of 0806 (Table 7). The result does not appear to be skewed by the exclusion of the "C" journals. This analysis is also presented graphically in Figure 1. 


\begin{tabular}{|r|l|c|}
\hline \multicolumn{1}{|c|}{$\begin{array}{c}\text { ANZ Fields of Research } \\
\text { Code }\end{array}$} & $\begin{array}{c}\text { No of } \\
\text { Journals }\end{array}$ \\
\hline 01 & Mathematical Sciences & 5 \\
\hline 0102 & Applied Mathematics & 5 \\
\hline 0103 & Numerical and Computational Mathematics & 2 \\
\hline 08 & Information and Computing Sciences & 13 \\
\hline 0801 & Artificial Intelligence and Image Processing & 8 \\
\hline 0802 & Computation Theory and Mathematics & 8 \\
\hline 0803 & Computer Software & 13 \\
\hline 0804 & Data Format & 13 \\
\hline 0805 & Distributed Computing & 9 \\
\hline 0806 & Information Systems & 117 \\
\hline 0807 & Library and Information Studies & 25 \\
\hline 0899 & Other Information and Computing Sciences & 7 \\
\hline 09 & Engineering & 2 \\
\hline 0903 & Biomedical Engineering & 2 \\
\hline 0913 & Mechanical Engineering & 1 \\
\hline 11 & Medical and Health Sciences & 1 \\
\hline 12 & Built Environment and Design & 1 \\
\hline 1203 & Design Practice and Management & 1 \\
\hline 1303 & Specialist Studies in Education & 1 \\
\hline 1403 & Econometrics & 1 \\
\hline 15 & Commerce, Management, Tourism and Services & 1 \\
\hline 1501 & Accounting, Auditing and Accountability & 1 \\
\hline 1502 & Banking, Finance and Investment & 1 \\
\hline 1503 & Business and Management & 1 \\
\hline 1604 & Human Geography & 1 \\
\hline 1605 & Policy and Administration & 1 \\
\hline 1606 & Political Science & 1 \\
\hline 17 & Psychology and Cognitive Sciences & 1 \\
\hline 1701 & Psychology & 1 \\
\hline 1702 & Cognitive Sciences & 1 \\
\hline 1801 & Law & 1 \\
\hline 2201 & Applied Ethics & 1 \\
\hline 2203 & Philosophy & 1 \\
\hline MD & Multidisciplinary & 1 \\
\hline & & 1 \\
\hline & & 1 \\
\hline
\end{tabular}

Table 6. ACPHIS nominated journals distributed according to ANZFoR code (All journals) 


\begin{tabular}{|r|l|r|}
\hline \multicolumn{2}{|c|}{ ANZ Fields of Research } & No journals \\
\hline 01 & Mathematical Sciences & 4 \\
\hline 0102 & Applied Mathematics & 1 \\
\hline 08 & Information and Computing Sciences & 7 \\
\hline 0801 & Artificial Intelligence and Image Processing & 4 \\
\hline 0802 & Computation Theory and Mathematics & 4 \\
\hline 0803 & Computer Software & 9 \\
\hline 0804 & Data Format & 6 \\
\hline 0805 & Distributed Computing & 3 \\
\hline 0806 & Information Systems & 58 \\
\hline 0807 & Library and Information Studies & 10 \\
\hline 0899 & Other Information and Computing Sciences & 1 \\
\hline 09 & Engineering & 2 \\
\hline 0903 & Biomedical Engineering & 2 \\
\hline 0913 & Mechanical Engineering & 1 \\
\hline 11 & Medical and Health Sciences & 1 \\
\hline 12 & Built Environment and Design & 1 \\
\hline 1303 & Specialist Studies in Education & 2 \\
\hline 1403 & Econometrics & 1 \\
\hline 15 & Commerce, Management, Tourism and Services & 2 \\
\hline 1503 & Business and Management & 20 \\
\hline 1605 & Policy and Administration & 1 \\
\hline 17 & Psychology and Cognitive Sciences & 1 \\
\hline 1701 & Psychology & 2 \\
\hline 1702 & Cognitive Sciences & 10 \\
\hline & & 153 \\
\hline
\end{tabular}

Table 7: ACPHIS nominated journals distributed according to ANZFoR code ("C" journals excluded)

This analysis emphasises the multidisciplinary nature of the information systems discipline. If it can be assumed that the distribution of these publications reflects the distribution of active research, it provides a novel breakdown of the distribution of information systems research.

\section{THE ISSUE OF SCOPUS TRACKING}

The issue of Scopus tracking of papers published in ERA ranked journals was thrust into prominence following the publication of the ERA 2010 Submission Guidelines (ARC, 2010a). It had been known for some time that Scopus was an official ERA information provider, but the submission guidelines included the following statement:

"For disciplines where citation analysis is used, the low volume threshold is 50 indexed journal articles. This means that no evaluation will be conducted for the relevant FoR for a given institution if the number of indexed journal articles over the six year research outputs reference period is fewer than 50 in any four-or two-digit FoR." (ARC, 2010a, p12)

The requirement for a minimum of 50 Scopus indexed papers in the ERA submission resulted in only six universities being assessed at the 0806 group level with the balance being assessed by aggregation as part of the 08 two-digit division rather than in their own right in the four-digit 0806 group (ARC 
2010c, p89). From Table 8 it can be seen that $23 \%$ of ACPHIS ranked journals included in ERA are not included in Scopus. The requirements and process for becoming indexed by Scopus (Scopus, 2010) are not onerous, but it is yet another issue which must be addressed by the discipline. Unless this action is taken on Scopus indexing, so that the 50 Scopus indexed articles hurdle can be passed, information systems will continue to be assessed as part of the 08 division.

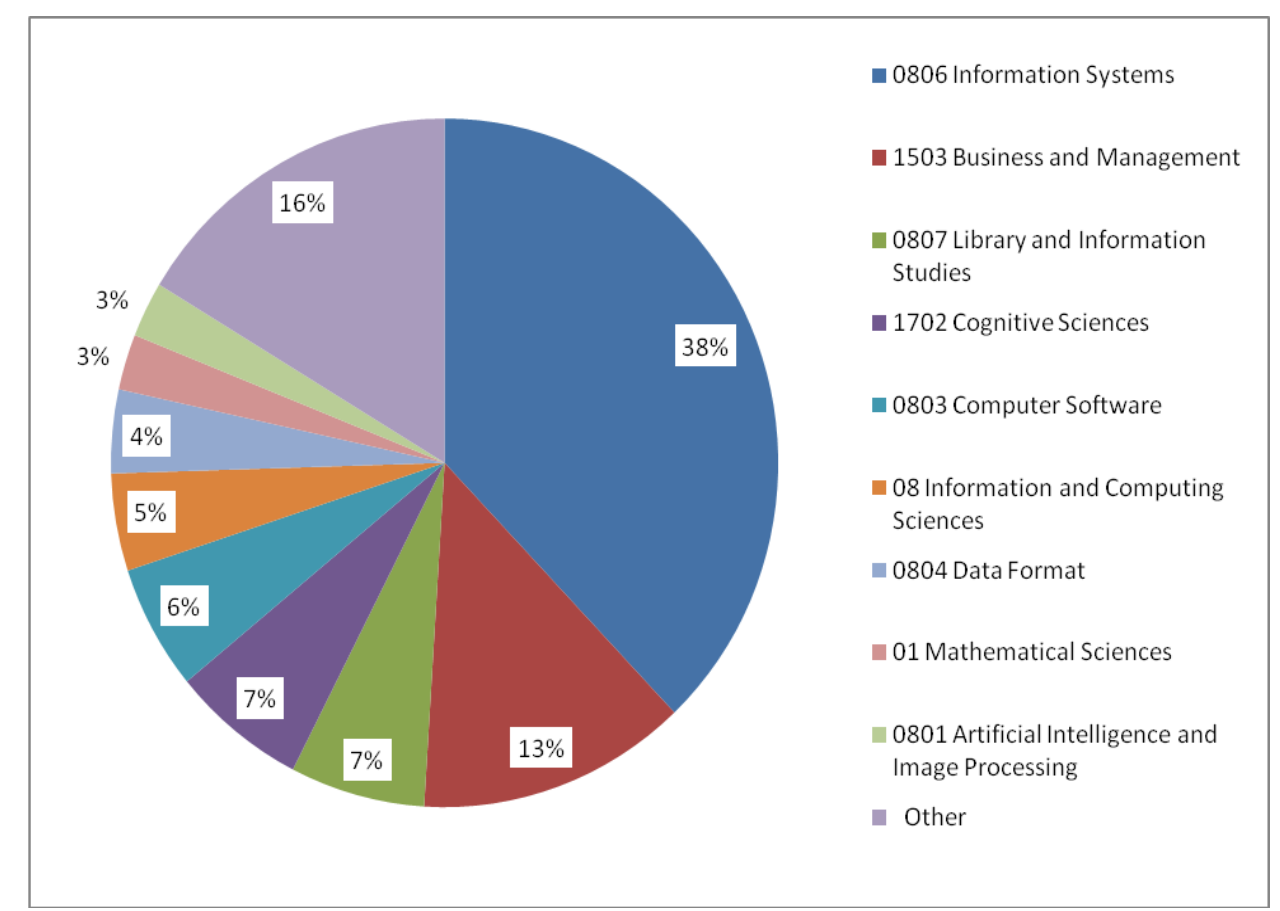

Figure 1. ACPHIS nominated journals distributed according to ANZFoR code (“C" $\mathrm{C}$ journals excluded)

\begin{tabular}{|l|l|l|}
\hline $\begin{array}{l}\text { ERA } \\
\text { Rank }\end{array}$ & $\begin{array}{l}\text { Scopus } \\
\text { In }\end{array}$ & Out \\
\hline A* & 26 & 0 \\
\hline A & 36 & 1 \\
\hline B & 42 & 10 \\
\hline C & 34 & 31 \\
\hline Total & 138 & 42 \\
\hline
\end{tabular}

Table 8. Scopus inclusion of ACPHIS ranked journals included in ERA

Table 9 lists the ACPHIS ranked journals with an ERA rank of A or B that are not indexed by Scopus. 


\begin{tabular}{|c|l|}
\hline ERA Rank & \multicolumn{1}{|c|}{ Title } \\
\hline A & Scandinavian Journal of Information Systems \\
\hline B & Australasian Journal of Information Systems \\
\hline B & e-Service Journal \\
\hline B & Educational Technology and Society \\
\hline B & Electronic Journal of IS Evaluation \\
\hline B & Human IT \\
\hline B & International Journal of Applied Management and Technology \\
\hline B & Journal of Global Information Technology Management \\
\hline B & Journal of Information Systems \\
\hline B & Journal of Research on Technology in Education \\
\hline B & The Information Management Journal \\
\hline
\end{tabular}

Table 9. ACPHIS ranked journals with an ERA rank of A or B which are not indexed by Scopus

\section{RANKING AND THE NUMBER OF YEARS OF PUBLICATION}

Mark Dodgson (Director of the Technology and Innovation Management Centre at the University of Queensland), writing in The Australian daily newspaper (Dodgson, 2010) commented that the ERA rankings "prioritises the established and relegates the emergent." To test this assertion, an analysis was made of the ERA ranking on ACPHIS recognised information systems journals based on the first year of publication of the journal. The results of this analysis are in Figure 2.

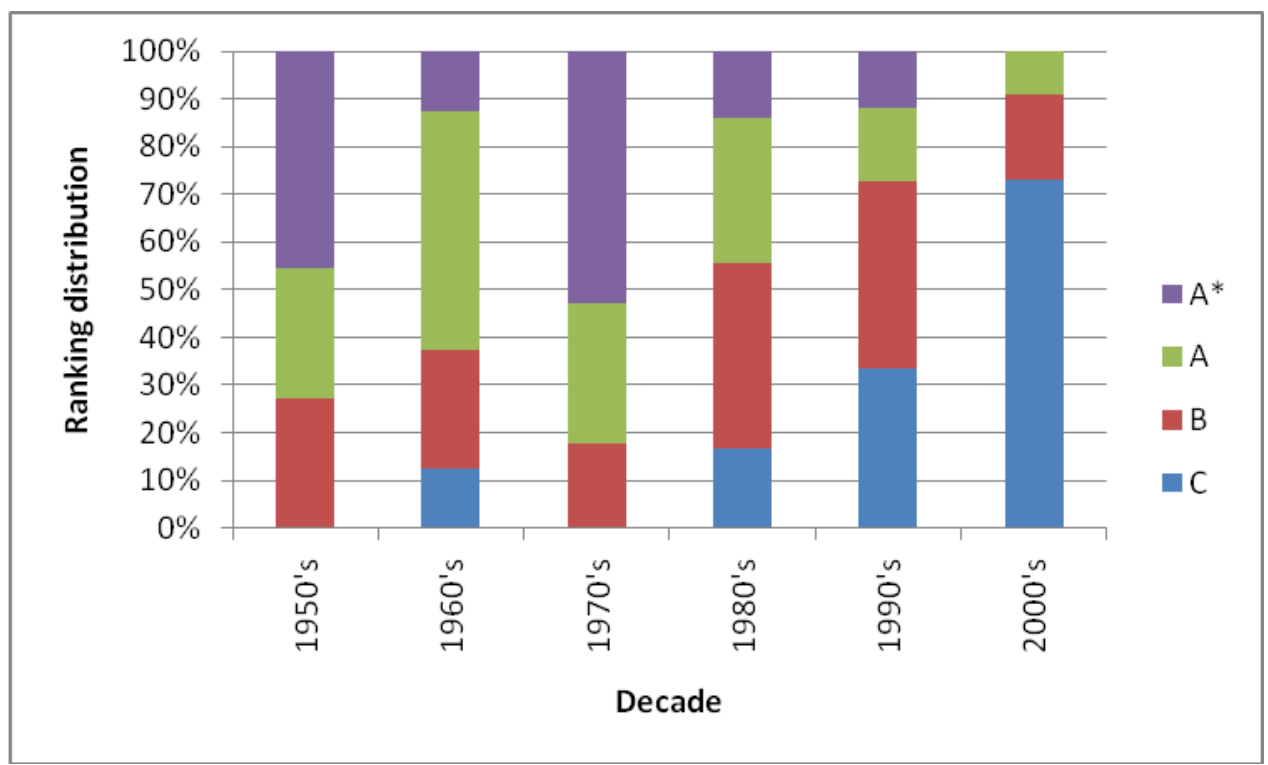

Figure 2. ERA ranking of ACPHIS ranked journals by decade of first publication $(n=180)$

Figure 2 indicates that older journals are more likely to have higher rankings. There are, however, only 180 journals in the ACPHIS list. Of those 180 journals, 107 were published between 1990 and 2009. This relatively short history of information systems as a discipline may well be affecting the distribution. 
The analysis was repeated on all ERA ranked journals in the 15 ANZFoR division, that is all two and four-digit codes commencing with 15 . This division contains commerce, management, tourism and services. It was chosen as a related division with a longer history of publication and contains 1045 journals. The results of this analysis are in Figure 3.

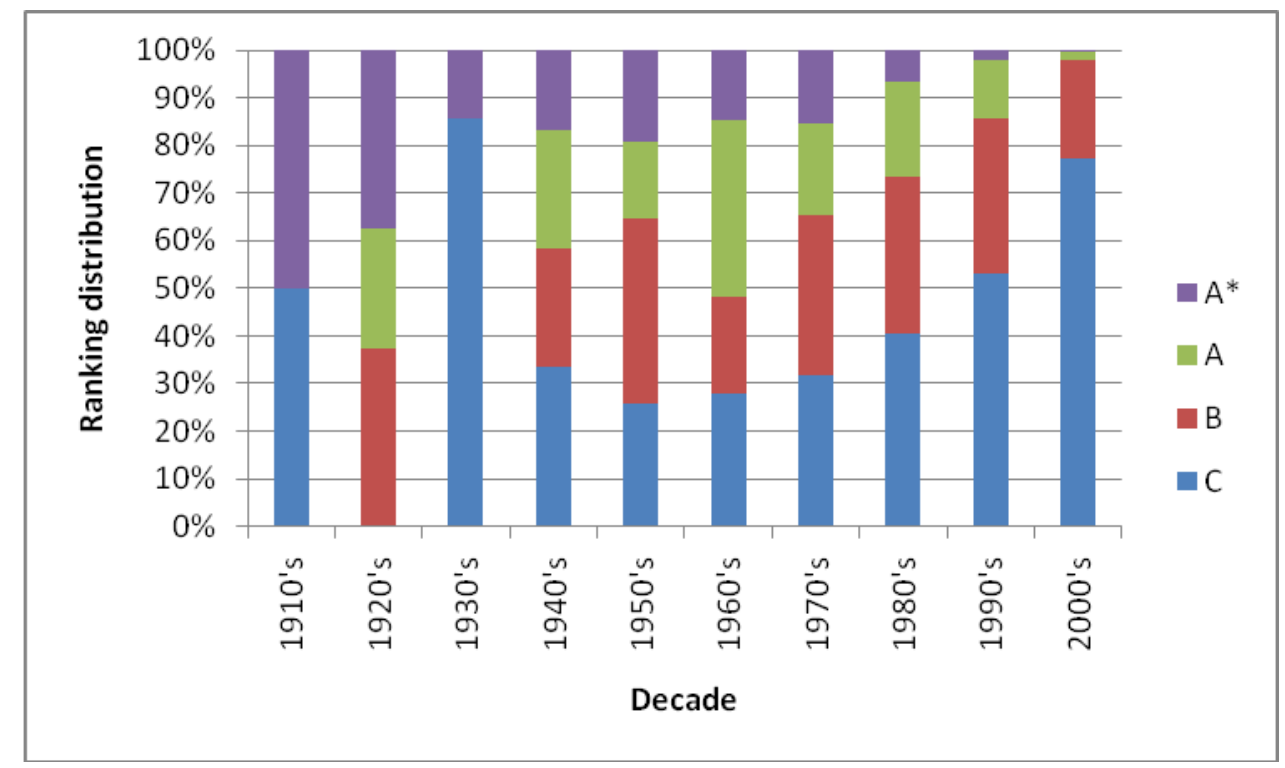

Figure 3. ERA ranking of journals in division 15 by decade of first publication $(n=1045)$

This distribution (Figure 3) would also appear to indicate that the older a journal is, the higher it is ranked by the ERA. As both of these examples use purposive samples rather than random samples, statistical analysis is inappropriate. A more detailed analysis over a wider range of journals using random sampling would allow a better supported conclusion, but is outside of the scope of this exercise.

The reason for this apparent bias is also problematic. It may well be that what is seen is the natural outcome of a selection process, whereby the weaker or lesser important journals cease publication over the years, rather than a conscious bias on the part of either those submitting or determining rankings of journals. An issue of greater significance is the degree to which this distribution will now remain fixed as a result of the ERA ranking process. It is a truism that the use of a new tool will change the behaviour of the tool users. The existence of the ERA rankings has attracted a large degree of interest from Australian academics. The website at Lamp (2010) attracts over 70,000 hits per month on the ERA journal and conference rankings. The existence and use of the ERA rankings has the potential to lock in the existing rankings - lower ranked or newer journals will find it hard to survive and progress.

\section{CONCLUSIONS}

The results of the 2010 ERA assessment have not yet been released and already preparations are being made for the review of the ERA journal rankings in 2011. This paper is a contribution to that process by analysing the ACPHIS submission and the fate of the rankings submitted. The multidisciplinary nature of the information systems discipline has been beneficial, as journals regularly used by information systems researchers, and yet ranked lower by ACPHIS as not being 
core to the information systems discipline, received a higher ranking based on submissions from the disciplines for which they were core journals. Very few journals proposed by ACPHIS to be ranked by ERA were rejected, and the majority of those were for clearly understandable reasons. The exclusion of Communications of the ACM, however, is not understood. The use of the ANZFoR codes allocated to journals suggested by ACPHIS has allowed an unprecedented view of the multidisciplinary nature of information systems. If it can be assumed that the distribution of journals reflects the distribution of research being undertaken, then the relative amount of research being done across specific disciplines can clearly be seen. The discipline must take action on the issue of information systems journals being indexed by Scopus, so that the 50 Scopus indexed articles hurdle can be passed and information systems assessed in its own right. The issue of the distribution of journal rankings as a function of the age of the journal should be monitored to determine whether the ERA ranking process is negatively affecting the evolution of publishing outlets.

\section{ACKNOWLEDGEMENTS}

The authors gratefully acknowledge the work of Emma Gliddon in preparing the data for the division 15 journal age analysis. Thanks also to the reviewers for their positive suggestions.

\section{REFERENCES}

ABS. (2008). Australian and New Zealand Standard Research Classification (ANZSRC), Australian Bureau of Statistics Publication 1297.0

ACPHIS. (2009). IS Journal Ranking, http://www.acphis.org.au/index.php?option=content\&task=section\&id=6\&Itemid=52 accessed 18 November 2010.

Anderson, D., \& Tressler, J.. (2009). "The 'Excellence in Research for Australia' Scheme: A Test Drive of Draft Journal Weights with New Zealand Data”. Agenda: a Journal of Policy Analysis and Reform, 16(4), 7-24.

ARC (2008a). The Excellence in Research for Australia (ERA) Initiative, http://www.arc.gov.au/era/ accessed 16 November 2010.

ARC (2008b). Excellence in Research for Australia, Consultation Paper, Australian Research Council, Canberra.

ARC (2009). ERA Indicators Consultation Paper, Australian Research Council, Canberra.

ARC. (2010a). ERA 2010 Submission Guidelines, Australian Research Council, Canberra.

ARC (2010b). ERA 2010 Ranked Outlets, http://www.arc.gov.au/era/era_journal_list.htm accessed 16 November 2010.

ARC (2010c) ERA 2010 National Report, Australian Research Council, Canberra.

Bernius, S. (2010). "The impact of open access on the management of scientific knowledge." Online Information Review 34(4): 583-603.

Calver, M., G. Wardell-Johnson, et al. (2010). "What makes a journal international? A case study using conservation biology journals." Scientometrics 85(2): 387-400.

Clarke, R. (2009). "A Citation Analysis of Australian Information Systems Researchers: Towards a New ERA?" Australasian Journal of Information Systems 15(2): 23-44.

De Lange, P., B. O’Connell, et al. (2010). "The ERA: A Brave New World of Accountability for Australian University Accounting Schools." Australian Accounting Review 20(1): 24-37.

DEST (2006). RQF Guiding Principles. Canberra, Department of Education, Science and Training. 
Dodgson, M. (2010). "Loose the corporate straightjacket and set minds free". The Australian. Melbourne.

Fisher, J., G. Shanks, et al. (2007). "A Ranking List for Information Systems Journals." Australasian Journal of Information Systems 14(2): 5-18.

Fisher, J., G. Shanks, et al. (2009). "ERA Replaces RQF." Australasian Journal of Information Systems 15(2): 5-6.

Genoni, P. and G. Haddow (2009). "ERA and the Ranking of Australian Humanities Journals." Australian Humanities Review 46: 7-26.

Graham, L. J. (2008). "Rank and File: Assessing research quality in Australia." Educational Philosophy and Theory 40(7): 811-815.

Haslam, N. and P. Koval (2010). "Possible research area bias in the Excellence in Research for Australia (ERA) draft journal rankings." Australian Journal of Psychology 62(2): 112-114.

Hicks, D. (2009). "Evolving regimes of multi-university research evaluation." Higher Education 57(4): 393-404.

Huxley, A. (1946). Brave New World, Harper \& Brothers, New York.

Jarwal, S. D., A. M. Brion, et al. (2009). "Measuring research quality using the journal impact factor, citations and 'Ranked Journals': blunt instruments or inspired metrics?" Journal of Higher Education Policy and Management 31(4): 289 - 300.

King, J. E. and P. Kreisler (2008). "News from down under." On The Horizon 16(4): 289-292.

Lamp, J. W. (1998). Index of Information Systems Journals. http://lamp.infosys.deakin.edu.au/journals/ accessed 23 November 2010

Lamp, J. W. (2009). "Journal ranking and the dreams of academics." Online Information Review 33(4): 827-830.

Lamp, J. W. (2010). ERA Current Rankings Access. http://lamp.infosys.deakin.edu.au/era/ accessed 16 November 2010.

Michael Hall, C. (2010). "Publish and perish? Bibliometric analysis, journal ranking and the assessment of research quality in tourism." Tourism Management In Press, Corrected Proof.

Northcott, D. and S. Linacre (2010). "Producing Spaces for Academic Discourse: The Impact of Research Assessment Exercises and Journal Quality Rankings." Australian Accounting Review 20(1): 38-54.

Scopus. (2010). Title Suggestion Form http://suggestor.step.scopus.com/suggestTitle.cfm accessed 23 November 2010

Spongberg, M. (2010). "feminist publishing in a cold climate?: 'Australian Feminist Studies' and the new ERA of research." Feminist Review 95(1): 99-110. 